ИЗВЕСТИЯ АКАДЕМИИ НАУК ЭСТОНСКОП ССР. ТОМ 30 Химия. 1981, №2 4

\title{
К ВОПРОСУ О НАКОПЛЕНИИ АНИОННЫХ ПОВЕРХНОСТНО-АКТИВНЫХ ВЕЩЕСТВ В ПРИРОДНЫХ ВОДОЕМАХ И ИХ КОЛИЧЕСТВЕННОМ ОПРЕДЕЛЕНИИ
}

Один из аспектов изучения загрязненности природных водоемов синтетическими поверхностно-активными веществами (СПАВ) - исследование закономерностей их распределения в водной фазе и донных отложениях $\left[{ }^{1,2,3}\right]$. Установлено, что при этом решающую роль играют особенности химического строения молекулы СПАВ и физико-химические свойства материала донных отложений. В то же время не менее актуально изучение возможностей выделения названных веществ из донных отложений с целью последующего количественного определения [4]. В связи с изложенным, а также учитывая широкое использование анионных ПАВ $(a-П А В)[5]$, представляется интересным дальнейшее исследование их накопления в донных отложениях, особенностей десорбции и уточнение возможностей применения более оперативных методов количественного анализа.

Как известно, к наиболее употребляемым методам определения $a$-ПАВ относятся экстракционно-фотометрические с использованием катионных красителей $\left[{ }^{6,7,8}\right]$. Стандартным методом считается колориметрический с метиленовым синим [ $\left.{ }^{7}\right]$, однако он имеет ряд недостатков, отмеченных в работах [6,9]. Методика с применением азура дает такие преимущества, как однократная экстракция, непосредственное фотометрирование экстракта без разбавления, увеличение чувствительности анализа $\left[{ }^{9}\right]$, что особенно важно при определении незначительных количеств $a$-ПАВ. Соответствующие исследования проведены нами на модельных растворах. В качестве эталона использован 1-n-додецилбензолсульфонат (ДДБС), синтезированный в секторе химии канцерогенов Института химии АН ЭССР [10․ Применяли водные растворы ДДБС с концентрацией $0,5-20$ мг/ $\Omega$ и образцы донных отложений различного состава из Псковско-Чудского озера (табл. 2), последние отбирали из поверхностного донного слоя и сушили при температуре $60-70{ }^{\circ} \mathrm{C}$ (во избежание разложения органической части отложений).

Навески донных отложений (5-20 2) помещали в стеклянные колбы с притертыми пробками емкостью 300 мл, заливали 200 мл раствора ДДБС определенной концентрации, встряхивали в течение 20 мин и отстаивали до осаждения мути. Начальную и конечную концентрации $a$-ПАВ в водной фазе определяли фотометрически с применением азура, а в контрольных опытах - с метиленовым синим.

Все опыты проводили в нейтральной среде $(\mathrm{pH} \sim 7)$. Количество сорбированного вещества оіределяли по разности начальной и конечной концентраций в водном растворе 'с расчетом на 1 г сухого материала донного отложения, Далее, навеску (1-4 г) этого материала в 
фильтровальной бумаге помещали в аппарат Сокслета, экстракцию сорбированного $a$-ПАВ производили дистиллированной водой [ $\left.{ }^{4}\right]$. Некоторую долю экстракта $(30-50$ мл, в зависимости от возможного количества растворенного в нем вещества) отбирали для определения в нем $a$-ПАВ путем использования азура, а в остальной части экстракта определяли ПАВ стандартным методом с метиленовым синим. Поскольку рекомендуется выделять $a$-ПАВ из донных отложений $70^{\circ}$-ным кипящим этанолом [1'], в ряде опытов эту методику использовали параллельно с вышеописанной с целью проверки результатов.

Оставшуюся аликвотную часть экстракта выпаривали досуха на водяной бане, остаток растворяли в 50 мл кипящей дистиллированной воды, после чего определяли ДДБС с использованием азура. Средние результаты приведены в табл. 1 и 2. Данные этих таблиц свидетельствуют о высокой сорбционной способности иеследуемых образцов донных отложений относительно ДДБС. При этом количество сорбированного из раствора вещества возрастает с увеличением его начальной концентрации в водной фазе.

Десорбция поглощенного донными отложениями ДДБС любым из описанных способов экстракции осуществляется с известными затруднениями и не всегда с полным извлечением. Важную. роль в этом процессе играет природа сорбирующего материала - органический и минеральный состав отложения [3]. Так, по нашим данным, из песчаных отложений в аппарате Сокслета дистиллированной водой извлекается примерно от 60 до $90 \%$ сорбированного СПАВ (табл. 2). В этом случае метод с применением азура не встречает возражений. Из иловых донных отложений всеми указанными способами удается извлечь лишь сравнительно небольшую долю поглощенного вещества, причем максимальная степень извлечения $(60 \%)$ достигается при использовании в качестве экстрагента дистиллированной воды (количественное определение СПАВ с метиленовым синим).

Серия предварительных экспериментов по экстракции ДДБС из иловых донных отложений кипящим этанолом показывает, что во многих случаях, независимо от используемого красителя конечный результат определения искажается под влиянием органической части отложений. Поэтому представляется более целесообразным остановиться на обработке иловых донных отложений дистиллированной водой с дальнейшим использованием стандартного метода определения $a$-ПАВ.

В то же время, независимо от способа экстракции, в большинстве случаев при экстракционно-фотометрическом методе определения $a$-ПАВ в иловых донных отложениях с применением азура конечный результат получается заниженным. Это подтвердилось при исследовании загрязненности донных отложений Псковско-Чудского озера (табл. 3). Сказанное не исключает возможности использования азура при анализе водной фазы с низкой концентрацией $a$-ПАВ.

С целью выявления фактора, затрудняющего десорбцию дДБС, и предотвращения его отрицательного воздействия, нами была испытана следующая методическая операция: образец илового донного отложения (навеска 10 2) предварительно подвергали двукратной обработке хлороформом $(200 \mathrm{M})$ в течение 15 мин, что позволило удалить из него органические компоненты. Обработанный таким образом материал илового отложения по описанной выше методике обрабатывался далее модельным водным раствором ДДБС, затем в нем производилось определение количества сорбированного СПАВ (табл. 1, 2). Результаты данного опыта показывают, что количество сорбированного этим способом вещества мало отличается от установленного для той же, но 
Таблица 1

Количественная характеристика процесса сорбции дДБС донными отложениями Псковско-Чудского оз.

\begin{tabular}{|c|c|c|c|c|c|c|}
\hline \multirow{2}{*}{ 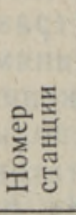 } & \multirow{2}{*}{$\begin{array}{c}\text { Характеристика } \\
\text { донного отложения }\end{array}$} & \multicolumn{2}{|c|}{$\begin{array}{c}\text { Концентрация } \\
\text { раствора, } \\
\text { ДДБС, }, \text { ма/л }\end{array}$} & \multirow{2}{*}{$\begin{array}{c}\text { Кол-во } \\
\text { сорбен- } \\
\text { та, г }\end{array}$} & \multicolumn{2}{|c|}{$\begin{array}{c}\text { Сорбировано } \\
\text { ДДБС }\end{array}$} \\
\hline & & $\begin{array}{l}\text { началь- } \\
\text { ная }\end{array}$ & $\begin{array}{l}\text { конеч- } \\
\text { ная }\end{array}$ & & ML & $M z / 2$ \\
\hline 21 & Ил с примесью минеральных частиц & $\begin{array}{r}1,00 \\
20,00\end{array}$ & $\begin{array}{l}0,01 \\
8,80\end{array}$ & $\begin{array}{l}10 \\
10\end{array}$ & $\begin{array}{l}0,20 \\
2,24\end{array}$ & $\begin{array}{l}0,020 \\
0,220\end{array}$ \\
\hline 21 & $\begin{array}{l}\text { Ил с примесью минеральных частиц, } \\
\text { обработанный хлороформом }\end{array}$ & 1,00 & 0,30 & 10 & 0,14 & 0,14 \\
\hline $7 \mathrm{a}$ & Песок с примесью иловых частиц & $\begin{array}{l}0,50 \\
1,00 \\
0,50 \\
1,00 \\
0,50 \\
1,00\end{array}$ & $\begin{array}{l}0,20 \\
0,60 \\
0,20 \\
0,20 \\
0,10 \\
0,10\end{array}$ & $\begin{array}{r}5 \\
5 \\
10 \\
10 \\
20 \\
20\end{array}$ & $\begin{array}{l}0,06 \\
0,08 \\
0,06 \\
0,16 \\
0,08 \\
0,18\end{array}$ & $\begin{array}{l}0,012 \\
0,016 \\
0,006 \\
0,016 \\
0,004 \\
0,0 \times 9\end{array}$ \\
\hline
\end{tabular}

Примечание: начальная и конечная концентрации ДДБС определялись экстракционно-фотометрическим методом с применением азура.

Таб̆лица 2

Выделение и определение ДДБС, сорбированного на донных отложениях Псковско-Чудского оз.

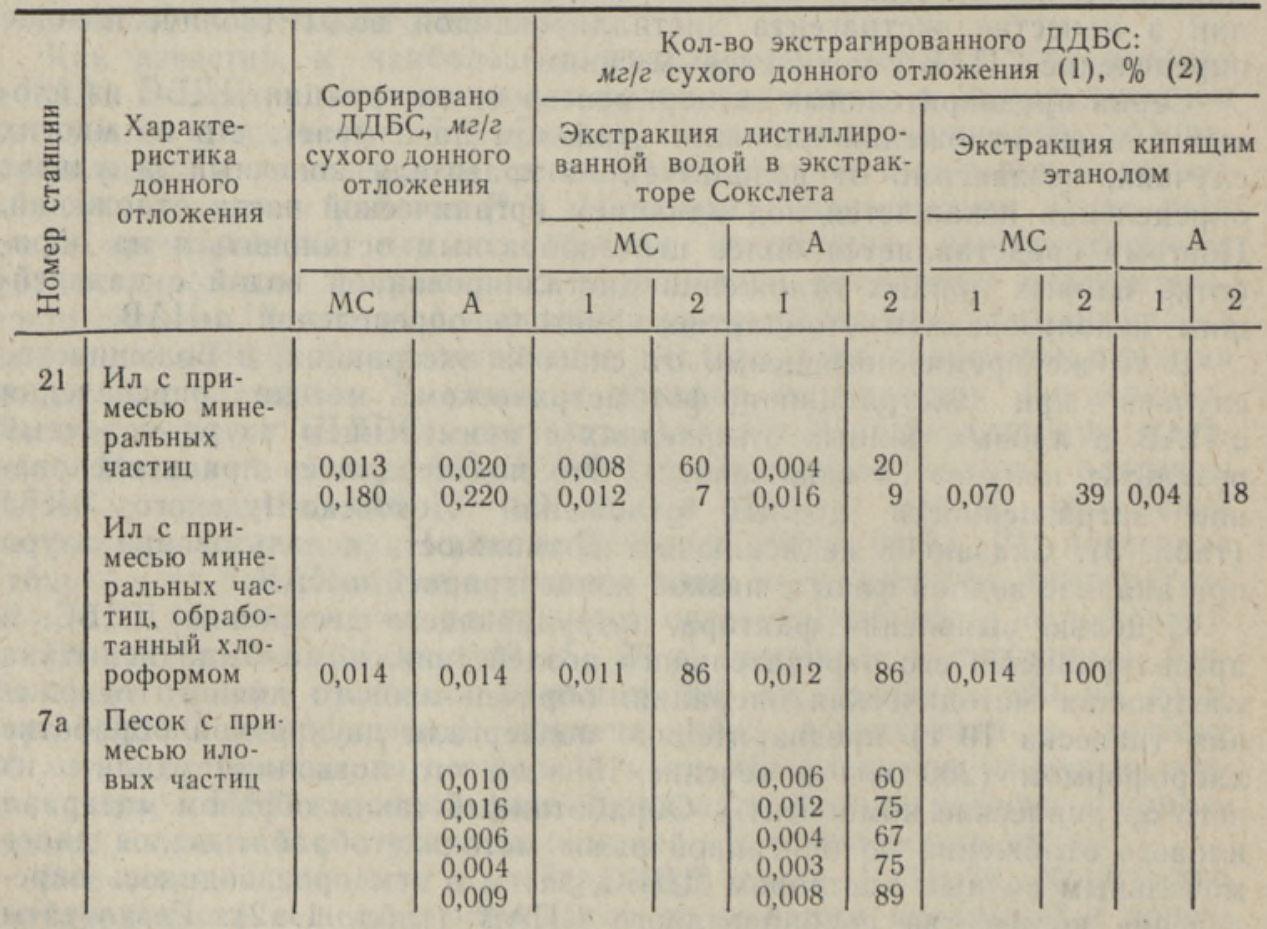

П р и м е ч а н и : $\mathrm{MC}-$ метнленовый синий, А - азур. 
Таблица 3

Содержание $а$-ПАВ в воде * и донных отложениях ** Псковско-Чудского оз. (1979) по месяцам

\begin{tabular}{|c|c|c|c|c|c|c|c|c|c|c|c|c|}
\hline \multirow{3}{*}{ 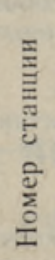 } & \multirow{3}{*}{$\begin{array}{c}\text { Место отбора } \\
\text { пробы }\end{array}$} & \multirow{3}{*}{$\begin{array}{c}\text { Характе- } \\
\text { рнстика } \\
\text { диа }\end{array}$} & \multirow{3}{*}{$\begin{array}{l}\text { Март } \\
\begin{array}{c}\text { в воде } \\
\text { Mz/л }\end{array} \\
\text { MC }\end{array}$} & \multirow{3}{*}{$\begin{array}{c}\text { Июнь } \\
\text { в воде } \\
\text { M2/л } \\
\text { MC }\end{array}$} & \multicolumn{3}{|c|}{ Август } & \multicolumn{5}{|c|}{ Октябрь } \\
\hline & & & & & \multicolumn{2}{|c|}{$\begin{array}{c}\text { в донных } \\
\text { отложен., } \\
\text { мг/кг }\end{array}$} & \multirow{2}{*}{$\begin{array}{c}\text { в воде } \\
\text { мг/л } \\
\text { MC }\end{array}$} & \multicolumn{2}{|c|}{$\begin{array}{l}\text { в донных } \\
\text { отложен., } \\
\text { мг/кг }\end{array}$} & \multirow{2}{*}{$\begin{array}{c}\begin{array}{c}\text { воде } \\
\text { ма/л }\end{array} \\
\mathrm{MC}\end{array}$} & \multicolumn{2}{|c|}{$\begin{array}{c}\text { в донных } \\
\text { отложен., } \\
\text { ма/ка }\end{array}$} \\
\hline & & & & & MC & A & & MC & A & & MC & A \\
\hline 21 & $\begin{array}{l}0,5 \text { км к северо- } \\
\text { западу от усть } \\
\text { р. Великой }\end{array}$ & $\begin{array}{l}\text { Рыхлый } \\
\text { нл с при- } \\
\text { месями }\end{array}$ & 0,02 & 0,02 & 6,0 & 4,0 & 0,02 & 6,0 & & 0,02 & 1,5 & 1 \\
\hline 24 & $\begin{array}{l}1,5 \text { км от д. } \mathrm{Pa}- \\
\text { сокпель }\end{array}$ & Ил & 0,03 & 0,02 & 6,0 & & 0,02 & 8,5 & 2 & 0,03 & 5,0 & 3,0 \\
\hline $27 \mathrm{a}$ & $\begin{array}{l}y \text { устья р. Суур- } \\
\text { Эмайыги }\end{array}$ & $\begin{array}{l}\text { Песок } \\
\text { с илом }\end{array}$ & 0,06 & 0,03 & 6,0 & & 0,01 & 2,8 & & 0,03 & 5,1 & 1,0 \\
\hline 12 & $\begin{array}{l}61 \text { км к югу от } \\
\text { устья р. Ала- } \\
\text { йыги }\end{array}$ & Песок & & 0,01 & 5,0 & 4,3 & 0,02 & 2,9 & & 0,02 & 4,0 & 2,5 \\
\hline $7 \mathrm{a}$ & $\begin{array}{l}0,5 \text { км к западу } \\
\text { от устья р. } \\
\text { Гдовки }\end{array}$ & $\begin{array}{l}\text { Песок } \\
\text { с при- } \\
\text { месями и }\end{array}$ & & 0,04 & & & 0,01 & 5,0 & 4,0 & 0,03 & 5,0 & 1,0 \\
\hline 25 & $\begin{array}{l}\text { У устья р. Нар- } \\
\text { ва }\end{array}$ & Песок & & 0,02 & & & 0,00 & 3,2 & & 0,02 & 1,1 & 2,0 \\
\hline 10 & $\begin{array}{l}31 \text { км к югу от } \\
\text { устья } \text { р. Ала- } \\
\text { йыги }\end{array}$ & $\begin{array}{l}\text { Рыхлый } \\
\text { ил }\end{array}$ & & & & & 0,03 & 11,5 & & 0,01 & 4,0 & 2,0 \\
\hline
\end{tabular}

* Содержание $a$-ПАВ в воде не превышало предельно допустимой концентрации, которая не установлена для донных отложений. МС - метиленовый синий, А - азур. ** Экстракция дистиллированной водой в аппарате Сокслета.

не обработанной хлороформом системы, однако степень извлечения его при десорбции с применением обоих методов экстракции оказалась заметно выше. При этом конечные результаты определения с применением азура или метиленового синего удовлетворительно согласуются между собой.

В итоге следует, во-первых, указать на ограниченную пригодность метода количественного определения $a$-ПАВ с использованием красителя азура при анализе донных отложений природных водоемов и, вовторых, предупредить о возможности неполного выделения сорбированного $a$-ПАВ из донных отложений природных водоемов.

\section{ЛИТЕРАТУРА}

1. Че рня в в. М., Ш а м анаев Ш. Ш. Загрязнение природных вод синтетическими поверхностно-активными веществами и проблемы охраны от них водных источников. - Водные ресурсы, 1976, № 4, с. 135-142.

2. Шаманаев Ш. Ш., Яковлева Н. А., Черняева Л. Е., Черняев А. М. Особенности распределения СПАВ в системе «вода - донные отложения».В кн.: Материалы VI всесоюзного симпозиума по современным проблемам самоочнщения водоемов и регулирования качества воды. Ростов-на-Дону, 1979, ч. 1 , c. $182-184$. 
3. Каплин В. Т., Косогорова А. С., Зернова Л. С., Фесенко Н. С. Адсорбционная способность природных донных отложений по отношению к синтетическим поверхностно-активным веществам. - Гидрохимические материалы. Л., 1966, т. 13, с. $291-301$.

4. П ри йм а Н Р. Э., И рха Н. И. Сравнительная характеристика двух способов экстракции аннонных поверхностно-актнвных веществ ( $a$-ПАВ) нз донных отложений водоемов. - Водные ресурсы, 1980, № 6, с. 186-189.

5. С ергее в Е. П., Мо жа е в Е. А. Санитарная охрана водоемов. М., 1979.

6. Дедков Ю. М., Су бботин а Е. И. Методы определения поверхностно-активных веществ в сточных водах. - Заводск. лаборатория, 1977, № 12, с. $1428-$ 1432.

7. Л урье Ю. Ю. Унифицированные методы анализа вод. М., 1973.

8. Л ейте В. Определение органических загрязнителей питьевых, природных и сточных вод. М., 1975.

9. Векслер В. И., Деева В. Е., М аркович А. В., Мельтева Н., Н., Прохоренко Л. Г., Х авин 3. Н., Чупятова А. В. Усовершенство-

' ванный метод определения анионных поверхностно-активных веществ. - Гигиена и санитария, 1972 , № 5, с. $63-66$.

10. Чеку лае в В. А. Фотонницинрованное окисление линейных алкилбензолсульфонатов в водной среде. - Изв. АН ЭССР. Хим., 1979, т. 28, № 3, с. $217-219$.

11. Временные инструкции по определению некоторых загрязняющих веществ в донных отложениях и в воде. М., 1972.

Институт химии

Академии наук Эстонской ССР

Поступила в редакци: 3/VI 1981

Natalja IRHA, Reet PRIIMAN, M. GUBERGRITS

\section{ANIOONSETE PINDAKTIIVSETE AINETE SALVESTUMINE LOODUSLIKESSE VEEKOGUDESSE JA NENDE KVANTITATIIVNE MÄ̈RAMINE}

On uuritud asuuri kasutamise võimalust pindaktiivsete ainete, lähemalt 1-p-dodetșüülbenseensulfonaadi (DBS) ekstraktsioonfotomeetrilisel kvantitatiivsel määramisel. On kindlaks tehtud, et DBS sorbeerub hästi Peipsi järve mudas ja liivastes pōhjasetetes. DBS eraldatavuse aste sōltub pōhjasetete koostisest.

Natalya IRHA, Reet PRIIMAN, M. GUBERGRITS

\section{ISOLATION AND QUANTITATIVE DETERMINATION \\ OF ANIONIC SURFACE-ACTIVE SUBSTANCES \\ IN NATURAL WATER-BODIES}

In connection with extensive use of anionic surface-active substances (SAS) and due to the unfavourable consequences of their accumulation in natural water-bodies, their determination and distribution in the system «water-ground deposits» represent an urgent problem.

The possibilities of using azure by extractive-photometric quantitative analysis of anionic SAS in ground deposits has been considered on the basis of 1-p-isomer of dodecylbenzene sulfonate (DDBS).

DDBS has been established to sorbate well on silt and sandy ground deposits of Lake Peipsi-Pihkva. The degree of extraction of DDBS depends upon the composition of ground deposits. 